\title{
. \\ Withasomniferol D, a New Anti-Adipogenic Withanolide from the Roots of Ashwagandha (Withania somnifera)
}

\author{
Bum Soo Lee ${ }^{1, \dagger}{ }^{+}$Min Jeong Yoo ${ }^{1,+}$, Heesun Kang ${ }^{1,+}$, Seoung Rak Lee ${ }^{1}$, Sil Kim ${ }^{1}$, Jae Sik Yu ${ }^{1}$, Jin-Chul Kim ${ }^{2}{ }^{\mathbb{D}}$, \\ Tae Su Jang ${ }^{3}$, Changhyun Pang ${ }^{4, *}$ and Ki Hyun Kim ${ }^{1, * \mathbb{D}}$ \\ 1 School of Pharmacy, Sungkyunkwan University, Suwon 16419, Korea; kosboybs@naver.com (B.S.L.); \\ kch970513@naver.com (M.J.Y.); hskang428@g.skku.edu (H.K.); davidseoungrak@gmail.com (S.R.L.); \\ malin_1272@naver.com (S.K.); jsyu@bu.edu (J.S.Y.) \\ 2 Natural Product Informatics Research Center, KIST Gangneung Institute of Natural Products, \\ Gangneung 25451, Korea; jckim@kist.re.kr \\ 3 College of Medicine, Dankook University, Cheonan 31116, Korea; jangts@dankook.ac.kr \\ 4 School of Chemical Engineering, Sungkyunkwan University, Suwon 16419, Korea \\ * Correspondence: chpang@skku.edu (C.P.); khkim83@skku.edu (K.H.K.); Tel.: +82-31-290-7341 (C.P.); \\ +82-31-290-7700 (K.H.K.) \\ + These authors contributed equally to this study.
}

check for updates

Citation: Lee, B.S.; Yoo, M.J.; Kang H.; Lee, S.R.; Kim, S.; Yu, J.S.; Kim, J.-C.; Jang, T.S.; Pang, C.; Kim, K.H. Withasomniferol D, a New Anti-Adipogenic Withanolide from the Roots of Ashwagandha (Withania somnifera). Pharmaceuticals 2021, 14, 1017. https://doi.org/10.3390/ ph14101017

Academic Editors: Magdalena Kotańska, Amélia Pilar Rauter, Małgorzata Szafarz, Monika Kubacka and Réjean Couture

Received: 23 August 2021

Accepted: 30 September 2021

Published: 2 October 2021

Publisher's Note: MDPI stays neutral with regard to jurisdictional claims in published maps and institutional affiliations.

Copyright: (c) 2021 by the authors. Licensee MDPI, Basel, Switzerland. This article is an open access article distributed under the terms and conditions of the Creative Commons Attribution (CC BY) license (https:// creativecommons.org/licenses/by/ $4.0 /)$.
Abstract: Withania somnifera (Solanaceae), well-known as 'Indian ginseng' or 'Ashwagandha', is a medicinal plant that is used in Ayurvedic practice to promote good health and longevity. As part of an ongoing investigation for bioactive natural products with novel structures, we performed a phytochemical examination of the roots of $W$. somnifera employed with liquid chromatography-mass spectrometry (LC/MS)-based analysis. The chemical analysis of the methanol extract of $W$. somnifera roots using repeated column chromatography and high-performance liquid chromatography under the guidance of an LC/MS-based analysis resulted in a new withanolide, withasomniferol D (1). The structure of the newly isolated compound was elucidated by spectroscopic methods, including onedimensional (1D) and two-dimensional (2D) nuclear magnetic resonance (NMR) and high-resolution (HR) electrospray ionization (ESI) mass spectroscopy, and its absolute configuration was established by electronic circular dichroism (ECD) calculations. The anti-adipogenic activities of withasomniferol D (1) were evaluated using 3T3-L1 preadipocytes with Oil Red O staining and quantitative real-time polymerase chain reaction (qPCR). We found that withasomniferol D (1) inhibited adipogenesis and suppressed the enlargement of lipid droplets compared to the control. Additionally, the mRNA expression levels of adipocyte markers Fabp4 and Adipsin decreased noticeably following treatment with $25 \mu \mathrm{M}$ of withasomniferol D (1). Taken together, these findings provide experimental evidence that withasomniferol D (1), isolated from W. somnifera, exhibits anti-adipogenic activity, supporting the potential application of this compound in the treatment of obesity and related metabolic diseases.

Keywords: Withania somnifera; Solanaceae; withanolide; NMR; ECD; 3T3-L1 preadipocytes; adipogenesis

\section{Introduction}

Withania somnifera (L.) Dunal (the family of Solanaceae), commonly known as 'Ashwagandha' or 'Indian ginseng', is a perennial shrub widely distributed across India, Sri Lanka, South Africa, and the Mediterranean region [1]. This plant is used in Indian Ayurveda as a traditional medicine for various inflammatory diseases, such as diabetes and nervous and reproductive system disorders [2]. Recently, it is also being consumed as a functional food to promote health and longevity by enhancing immunity against extrinsic factors, delaying aging, and strengthening the body [3,4]. In practice, the extracts of W. somnifera roots are consumed as a dietary supplement in several forms, including powder, liquid, tablets, and capsules. W. somnifera has been widely studied for therapeutic purposes and possesses several pharmacological properties, including antioxidative, analgesic, antiulcerative, antiepileptic, and antibacterial properties [5]. This plant also shows positive 
therapeutic activities for treating anxiety, inflammation-related diseases, cognitive and neurological disorders, hyperlipidemia, and Parkinson's disease [6-8]. In addition, it possesses diverse types of chemical constituents, including alkaloids, steroids, saponins, and withanolides [9-11]. Taxonomically, W. somnifera is known to be a rich source of withanolides, which are ergostane-type steroidal lactones where the steroid skeleton is oxidized to form a $\delta$-lactone ring in the side chain and a 2-in-1-one system in the A-ring [12]. Withanolides are reported to exhibit diverse pharmacological effects, including anti-inflammatory, antitumor, hepatoprotective, antimicrobial, and immunosuppressive effects [13-19], which suggests that they are the most significant constituents responsible for the medicinal properties of W. somnifera [20].

As part of ongoing research to discover bioactive compounds in diverse natural resources [21-24], we have investigated bioactive phytochemicals from a methanol $(\mathrm{MeOH})$ extract of the roots of $W$. somnifera $[25,26]$. In our previous phytochemical exploration of $W$. somnifera roots, we identified six novel withanolides, namely withasilolides A-F, and seven known withanolides, and confirmed that five of the isolated withanolides showed cytotoxicity against several human cancer cells, including SK-MEL-2, HCT-15, A549, and SK-OV-3 [25]. Besides withanolides, we have also identified new phenylpropanoid esters (withaninsams A and B) in our recent study, along with phenolic compounds and alkaloids that showed anti-inflammatory potential via nitric oxide (NO) inhibition by reducing the protein expression of inducible NO synthase (iNOS) [26]. As part of ongoing research to search for bioactive natural products with novel structures from $W$. somnifera, we carried out a phytochemical exploration of $W$. somnifera roots combined with liquid chromatographymass spectrometry (LC/MS)-based analysis. Furthermore, the chemical analysis of the methanolic extracts of W. somnifera roots under LC/MS-based analysis led to the isolation of a new withanolide, withasomniferol D (1). Herein, we describe the purification and structural elucidation of compound $\mathbf{1}$ and its effect on de novo adipogenesis and lipid metabolism in 3T3-L1 adipocytes.

\section{Results and Discussion}

\subsection{Isolation of Compound $\mathbf{1}$}

The W. somnifera roots were extracted with $80 \%$ aqueous $\mathrm{MeOH}$ under reflux to obtain the crude $\mathrm{MeOH}$ extract by rotary evaporation. The $\mathrm{MeOH}$ extract was sequentially subjected to the solvent partition procedure using four organic solvents, including hexane, dichloromethane, ethyl acetate, and $n$-butanol, to yield each solvent fraction (Figure 1). LC/MS-based analysis of the solvent-partitioned fractions obtained in combination with our in-house UV library revealed that the $\mathrm{CH}_{2} \mathrm{Cl}_{2}$-soluble fraction was rich in withanolides. The intensive phytochemical investigation of the $\mathrm{CH}_{2} \mathrm{Cl}_{2}$-soluble fraction using successive column chromatography and preparative and semi-preparative HPLC purification (Figure 1), where the isolation was monitored by LC/MS analysis, led to the isolation of a novel withanolide (1) (Figure 1).

\subsection{Structural Elucidation of Compound $\mathbf{1}$}

Compound $\mathbf{1}$ was isolated as a white powder. Its molecular formula was determined to be $\mathrm{C}_{28} \mathrm{H}_{38} \mathrm{O}_{7}$, based on the NMR data (Table 1) and HR-ESIMS data, which showed the quasimolecular ion peak at $m / z 509.2505[\mathrm{M}+\mathrm{Na}]^{+}$(calculated for $\mathrm{C}_{28} \mathrm{H}_{38} \mathrm{NaO}_{7}, 509.2515$ ) in the positive mode. The IR spectrum of 1 displayed distinctive absorption bands for the hydroxy $\left(3716 \mathrm{~cm}^{-1}\right)$ functional unit and $\alpha, \beta$-unsaturated ketone $\left(1697 \mathrm{~cm}^{-1}\right)$ functional unit. The ${ }^{1} \mathrm{H}$ NMR data (Table 1) of 1 combined with the data from the HSQC experiment showed the presence of proton signals for four methyls $\left(\delta_{\mathrm{H}} 0.96(3 \mathrm{H}, \mathrm{s}), 1.18(3 \mathrm{H}, \mathrm{s}), 1.34\right.$ $(3 \mathrm{H}, \mathrm{s})$, and $1.89(3 \mathrm{H}, \mathrm{s})$ ), seven methylenes $\left(\delta_{\mathrm{H}} 1.35 / 2.74(\right.$ each $1 \mathrm{H}, \mathrm{m}), 1.37 / 1.85$ (each $1 \mathrm{H}$, $\mathrm{m}$, overlap), 1.37/2.08 (each $1 \mathrm{H}, \mathrm{m}$, overlap), 1.58/2.03 (each $1 \mathrm{H}, \mathrm{m}$ ), $2.53(1 \mathrm{H}, \mathrm{dd}, J=19.0$, $5.0 \mathrm{~Hz}) / 2.68(1 \mathrm{H}, \mathrm{br} \mathrm{d}, J=19.0 \mathrm{~Hz})$, and $4.35(1 \mathrm{H}, \mathrm{d}, J=14.0 \mathrm{~Hz}) / 4.48(1 \mathrm{H}, \mathrm{d}, J=14.0 \mathrm{~Hz}))$, and nine methines $\left(\delta_{\mathrm{H}} 1.43(1 \mathrm{H}, \mathrm{m}), 1.54(1 \mathrm{H}, \mathrm{m}), 1.56(1 \mathrm{H}, \mathrm{m}), 1.78(1 \mathrm{H}, \mathrm{m}), 3.05(1 \mathrm{H}\right.$, $\mathrm{d}, J=4.0 \mathrm{~Hz}), 3.32(1 \mathrm{H}, \mathrm{m}), 4.22(1 \mathrm{H}, \mathrm{dd}, J=13.5,4.0 \mathrm{~Hz}), 5.85(1 \mathrm{H}, \mathrm{dd}, J=10.0,2.0 \mathrm{~Hz})$, 
and $6.59(1 \mathrm{H}, \mathrm{ddd}, J=10.0,5.0,2.0 \mathrm{~Hz}))$. The ${ }^{13} \mathrm{C}$ NMR data (Table 1$)$, combined with the data obtained from the HSQC and HMBC spectra, revealed 28 carbon resonances that were classified into four methyl groups $\left(\delta_{C} 11.8,13.6,14.5\right.$, and 20.9), seven methylenes $\left(\delta_{C} 21.4,21.6,22.8,25.7,36.5,40.2\right.$, and 61.2$)$, nine methines $\left(\delta_{C} 34.9,35.4,51.8,54.1,55.8\right.$, $56.7,81.8,128.8$, and 139.5), and eight non-protonated carbons $\left(\delta_{C} 43.7,50.8,73.2,75.1\right.$, $122.2,150.1,166.0$, and 203.3). Comprehensive scrutiny of the NMR spectral data suggested that the structure of 1 was very similar to that of withasomniferol A, previously identified in Indian ginseng by our group [25], but the apparent difference between the structures of 1 and withasomniferol A was identified in the $\delta$-lactone ring due to the discrepancy in the NMR signals corresponding to C-27 and C-28. The distinctive A/B ring pattern observed in $6 \alpha, 7 \alpha$-epoxy-5 $\alpha$-hydroxy-1-oxowitha-2-enolide [25] was present in compound 1 , similar to withasomniferol $\mathrm{A}$, which was clearly determined from the NMR signals at $\mathrm{C}-1\left(\delta_{\mathrm{C}} 203.3\right), \mathrm{C}-2\left(\delta_{\mathrm{H}} 5.85(1 \mathrm{H}, \mathrm{dd}, J=10.0,2.0 \mathrm{~Hz})\right.$ and $\left.\delta_{\mathrm{C}} 128.8\right)$, and $\mathrm{C}-3\left[\delta_{\mathrm{H}} 6.60(1 \mathrm{H}\right.$, ddd, $J=10.0,5.0$ and $2.0 \mathrm{~Hz})$ and $\delta_{\mathrm{C}} 139.5$ ] for an $\alpha, \beta$-unsaturated ketone; $\mathrm{C}-5\left(\delta_{\mathrm{C}} 73.2\right)$ for a hydroxylated quaternary carbon; and C-6 $\left(\delta_{\mathrm{H}} 3.05(1 \mathrm{H}, \mathrm{d}, J=4.0 \mathrm{~Hz})\right.$ and $\left.\delta_{\mathrm{C}} 55.8\right)$ and C-7 $\left(\delta_{\mathrm{H}} 3.32(1 \mathrm{H}, \mathrm{m})\right.$ and $\left.\delta_{\mathrm{C}} 56.7\right)$ for an epoxy functional group. The partial structure of 1 was also supported by the interpretation of the key HMBC correlations from H-2/C-3, H-3/C-1, $\mathrm{H}-3 / \mathrm{C}-5, \mathrm{H}_{3}-19 / \mathrm{C}-5, \mathrm{H}_{3}-19 / \mathrm{C}-1$, and H-6/C-10, as well as the key COSY correlations from H-2 to H-4 and H-6 to H-9 (Figure 2). Importantly, the partial structure of the $\delta$-lactone ring was determined by the key COSY correlations from $\mathrm{H}-22$ to $\mathrm{H}-23$ and the key $\mathrm{HMBC}$ correlations of H-22/C-24, $\mathrm{H}_{3}-27 / \mathrm{C}-24, \mathrm{H}_{3}-27 / \mathrm{C}-26, \mathrm{H}_{3}-27 / \mathrm{C}-25, \mathrm{H}_{3}-28 / \mathrm{C}-23, \mathrm{H}_{3}-28 / \mathrm{C}-24$, and $\mathrm{H}_{3}-28 / \mathrm{C}-25$ (Figure 2), which verified the $\delta$-lactone ring structure of 1 (Figure 1 ). In conclusion, we deduced that the hydroxylation of C-27 in withasomniferol A shifted to $\mathrm{C}-28$ in 1 . The complete gross structure of 1 was further confirmed by a detailed inspection of the COSY and HMBC data (Figure 2).

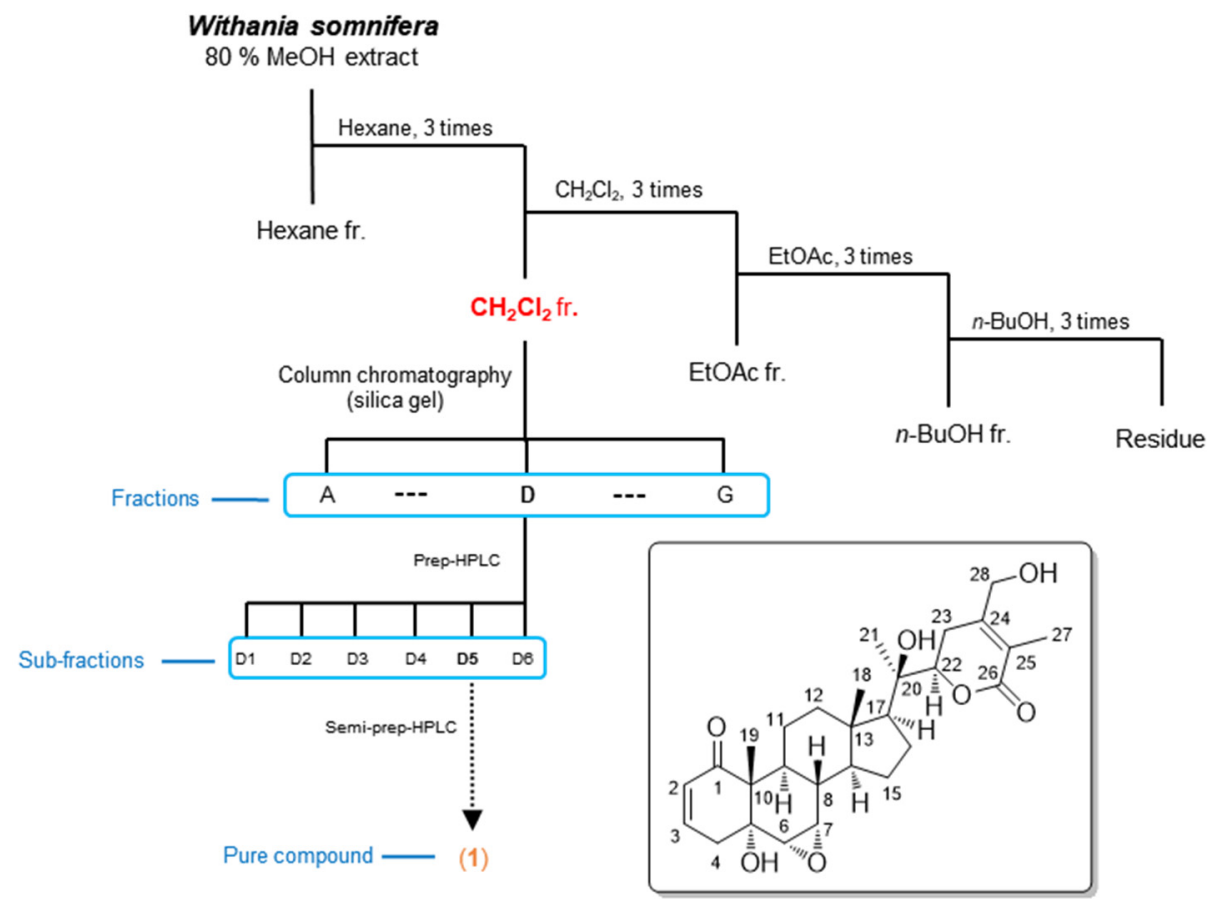

Figure 1. The separation scheme and chemical structure of compound $\mathbf{1 .}$

The absolute configuration of $\mathbf{1}$ was determined by examining the correlations obtained from the ROESY experiment, vicinal proton coupling constants in the ${ }^{1} \mathrm{H}$ NMR data, and ECD data. The $\alpha$-position of the epoxy group between C-6 and C-7 was confirmed by the ROESY correlations of $\mathrm{H}-7 / \mathrm{H}-8, \mathrm{H}-6 / \mathrm{H}-7, \mathrm{H}-6 / \mathrm{H}_{3}-19$, and $\mathrm{H}_{3}-19 / \mathrm{H}-8$ and the characteristic coupling constant of $4.0 \mathrm{~Hz}$ between $\mathrm{H}-6$ and $\mathrm{H}-7$ (Figure 3), which also suggested a trans-linkage in the conformation of the A/B ring in 1, based on the 
smaller coupling constant of $0-2 \mathrm{~Hz}$ for $\mathrm{H}-6$, which is typical in cis-linkages $[25,27,28]$. The trans-linkage for the $\mathrm{A} / \mathrm{B}$ ring was further verified by the negative Cotton effect around $340 \mathrm{~nm}$ in the ECD measurement of 1 [25], and the configurations at C-5, C-6, and C-7 were assigned accordingly, as depicted in Figure 1. The stereochemistry of H-22 $(J=13.5$ and $3.5 \mathrm{~Hz}$ ) was determined to be $\alpha$-form on the basis of the typical coupling constants of $\mathrm{H}-22$ reported in a previous study, where the ${ }^{1} \mathrm{H}$ NMR data of $\mathrm{H}-22 \alpha$ demonstrated a doublet of doublets with two different coupling constants $(J=9.0-13.8$ and $0.5-4.0 \mathrm{~Hz})[25,27]$, while the ${ }^{1} \mathrm{H}$ NMR data of $\mathrm{H}-22 \beta$ showed two similar coupling constants $(J=2.5-7.0$, 2.0-5.0 Hz) [28]. The $\alpha$-orientation of $\mathrm{H}-22$ was also verified by the ROESY correlations of $\mathrm{H}-16 \alpha / \mathrm{H}-22$ and $\mathrm{H}-17 / \mathrm{H}-22$ (Figure 3). In fact, the absolute configuration of C-22 was unambiguously confirmed as $R$ based on the positive Cotton effect at $260 \mathrm{~nm}$ derived from the $\mathrm{n} \rightarrow \pi^{*}$ transition of the $\alpha, \beta$-unsaturated $\delta$-lactone $[25,28]$. In addition, the ROESY correlations of $\mathrm{H}_{3}-21 / \mathrm{H}-17$ and $\mathrm{H}_{3}-21 / \mathrm{H}-23 \alpha$ indicated the $R$-configuration of the hydroxylated quaternary carbon C-20. Finally, to confirm the absolute configuration of 1 , the ECD data of two possible isomers, $1 \mathrm{a}(5 R, 6 S, 7 S, 8 S, 9 S, 10 R, 13 S, 14 S, 17 S, 20 R, 22 R)$ and $1 \mathrm{~b}$ $(5 S, 6 R, 7 R, 8 R, 9 R, 10 S, 13 R, 14 R, 17 R, 20 S, 22 S)$, were subjected to ECD calculations. The ECD calculation results revealed that the ECD curve of 1a (blue line) was matched with the experimentally determined ECD spectrum of 1 (Figure 4). Therefore, the chemical structure of 1 , including the absolute configuration, was determined, as illustrated in Figure 1, and its trivial name was withasomniferol D.

Table 1. ${ }^{1} \mathrm{H}(800 \mathrm{MHz})$ and ${ }^{13} \mathrm{C}$ NMR $(200 \mathrm{MHz})$ data of compound 1 in $\mathrm{CDCl}_{3}(\delta$ in ppm $){ }^{\mathrm{a}}$.

\begin{tabular}{|c|c|c|}
\hline \multirow{2}{*}{ Position } & \multicolumn{2}{|c|}{1} \\
\hline & $\delta_{\mathrm{H}}(J$ in $\mathrm{Hz})$ & $\delta_{\mathrm{C}}$ \\
\hline 1 & & $203.3 \mathrm{~s}$ \\
\hline 2 & $5.85 \mathrm{dd}(10.0,2.0$ & $128.8 \mathrm{~d}$ \\
\hline 3 & 6.59 ddd $(10.0,5.0,2.0)$ & $139.5 \mathrm{~d}$ \\
\hline $4 \alpha$ & $2.53 \mathrm{dd}(19.0,5.0)$ & $36.5 \mathrm{t}$ \\
\hline $4 \beta$ & 2.68 br d $(19.0)$ & \\
\hline 5 & & $73.2 \mathrm{~s}$ \\
\hline 6 & $3.05 \mathrm{~d}(4.0)$ & $55.8 \mathrm{~d}$ \\
\hline 7 & $3.32 \mathrm{~m}$ & $56.7 \mathrm{~d}$ \\
\hline 8 & $1.78 \mathrm{~m}$ & $34.9 \mathrm{~d}$ \\
\hline 9 & $1.56 \mathrm{~m}$ & $35.4 \mathrm{~d}$ \\
\hline 10 & & $50.8 \mathrm{~s}$ \\
\hline $11 \alpha$ & $2.74 \mathrm{~m}$ & $21.4 \mathrm{t}$ \\
\hline $11 \beta$ & $1.35 \mathrm{~m}$ & \\
\hline $12 \alpha$ & $1.37 \mathrm{~m}$ & $40.2 \mathrm{t}$ \\
\hline $12 \beta$ & $2.08 \mathrm{~m}$ & \\
\hline 13 & & $43.7 \mathrm{~s}$ \\
\hline 14 & $1.43 \mathrm{~m}$ & $51.8 \mathrm{~d}$ \\
\hline $15 \alpha$ & $1.85 \mathrm{~m}$ & $22.8 \mathrm{t}$ \\
\hline $15 \beta$ & $1.37 \mathrm{~m}$ & \\
\hline $16 \alpha$ & $1.58 \mathrm{~m}$ & $21.6 \mathrm{t}$ \\
\hline $16 \beta$ & $2.03 \mathrm{~m}$ & \\
\hline 17 & $1.54 \mathrm{~m}$ & $54.1 \mathrm{~d}$ \\
\hline 18 & $0.96 \mathrm{~s}$ & $13.6 \mathrm{q}$ \\
\hline 19 & $1.18 \mathrm{~s}$ & $14.5 \mathrm{q}$ \\
\hline 20 & & $75.1 \mathrm{~s}$ \\
\hline 21 & $1.34 \mathrm{~s}$ & $20.9 \mathrm{q}$ \\
\hline 22 & $4.22 \mathrm{dd}(13.5,4.0)$ & $81.8 \mathrm{~d}$ \\
\hline $23 \alpha$ & $2.29 \mathrm{~m}$ & $25.7 \mathrm{t}$ \\
\hline $23 \beta$ & $2.60 \mathrm{~m}$ & \\
\hline 24 & & $150.1 \mathrm{~s}$ \\
\hline 25 & & $122.2 \mathrm{~s}$ \\
\hline 26 & & $166.0 \mathrm{~s}$ \\
\hline 27 & $1.89 \mathrm{~s}$ & $11.8 \mathrm{q}$ \\
\hline $28 \mathrm{a}$ & $4.35 \mathrm{~d}(14.0)$ & $61.2 \mathrm{t}$ \\
\hline $28 \mathrm{~b}$ & $4.48 \mathrm{~d}(14.0)$ & \\
\hline
\end{tabular}

${ }^{\mathrm{a}} J$ values are in parentheses and shown in $\mathrm{Hz} ;{ }^{13} \mathrm{C}$ nuclear magnetic resonance (NMR) assignments are based on the heteronuclear single quantum coherence (HSQC) and HMBC experiments. 


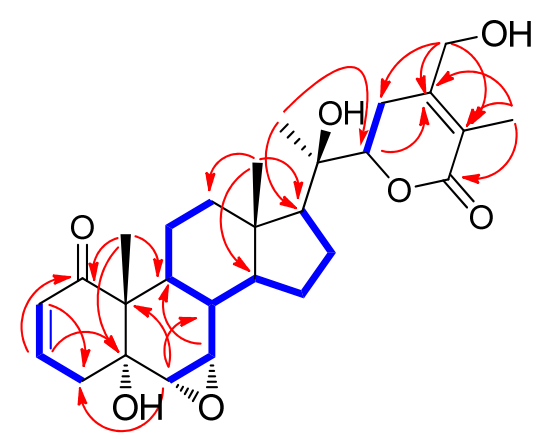

Figure 2. Key ${ }^{1} \mathrm{H}_{-}{ }^{1} \mathrm{H}$ correlation spectroscopy $\left({ }^{1} \mathrm{H}_{-}{ }^{1} \mathrm{H}\right.$ COSY $)(-)$ and heteronuclear multiple bond correlation $(\mathrm{HMBC})(\subsetneq)$ correlations for $\mathbf{1}$.

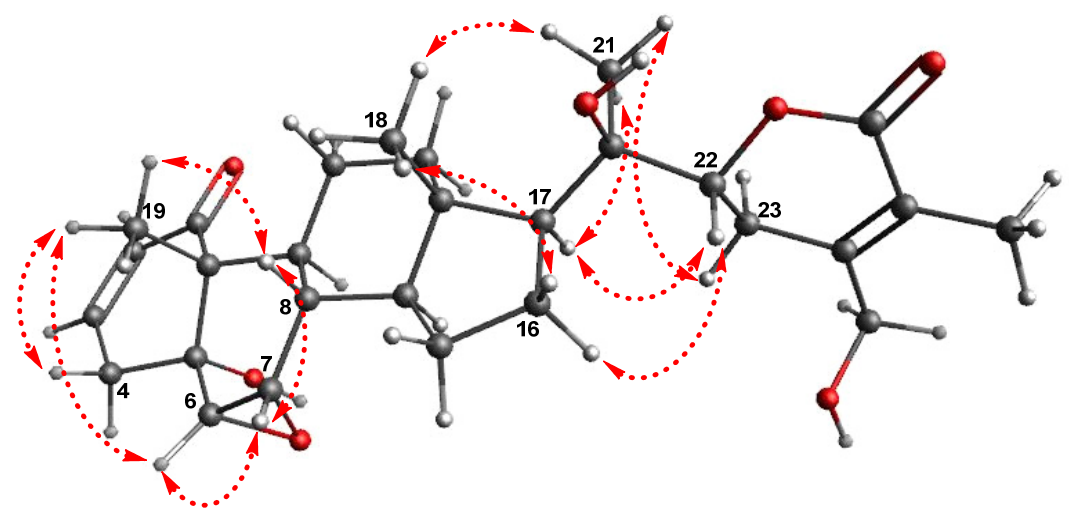

Figure 3. Key rotating-frame Overhauser enhancement spectroscopy (ROESY) correlations for 1.
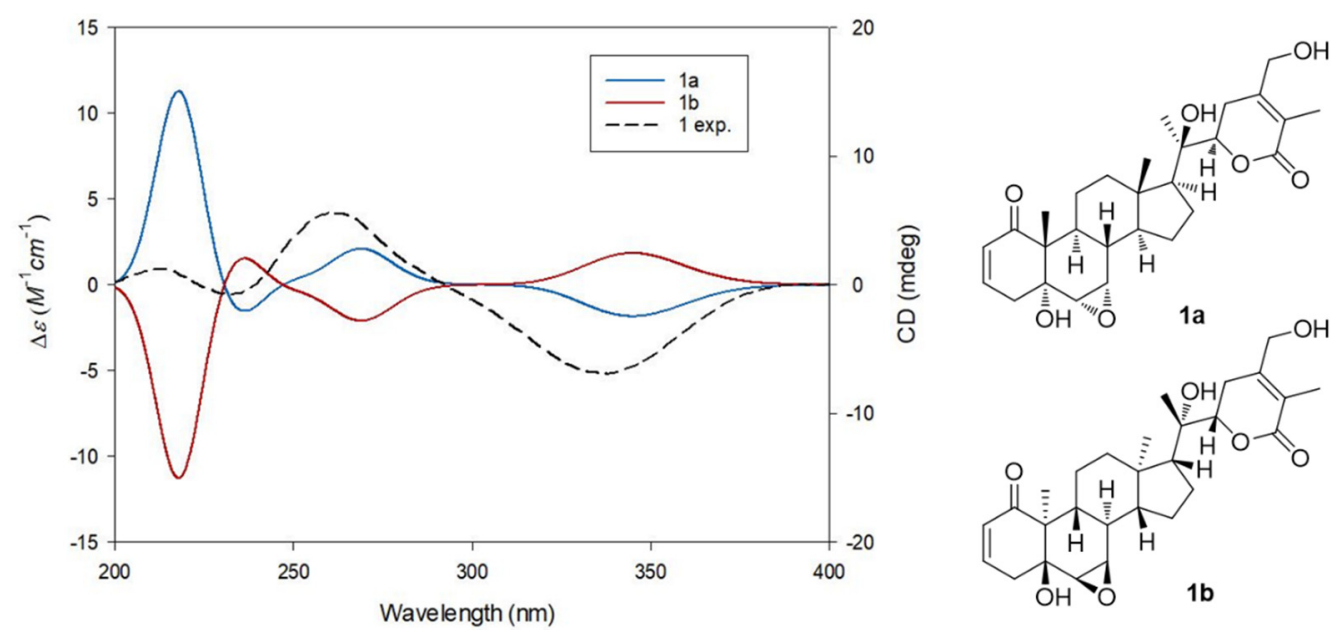

Figure 4. Experimental and calculated ECD data of $\mathbf{1}$.

\subsection{Evaluation of the Anti-Adipogenic Activity of Compound $\mathbf{1}$}

Obesity is a major health problem that results from the summation of multiple factors, including genetic, dietary, lifestyle-related, and environmental factors, which lead to the inordinate accumulation of body fat in adipose tissues [29]. Adipose tissue growth occurs with the differentiation of preadipocytes into adipocytes in the adipose tissues and the generation and collection of lipid droplets in adipocytes [30,31]. Therefore, bioactive compounds that prevent adipogenesis and lipogenesis have been considered as potential therapeutic strategies for the prevention of obesity and metabolic diseases. Recently, withaferin $\mathrm{A}$, one of the most representative withanolides found in $W$. somnifera, was found to exhibit anti-adipogenic effects in 3T3-L1 adipocytes by reducing the lipid accumulation and downregulating the expression of key activators of adipogenesis, including the peroxisome 
proliferator-activated receptor gamma (PPAR $\gamma), \mathrm{CCAAT} /$ enhancer binding protein alpha $(\mathrm{C} / \mathrm{EBP} \alpha)$, and the adipocyte fatty acid binding protein [32]. Therefore, the anti-adipogenic activities of withasomniferol D (1) were evaluated using 3T3-L1 preadipocytes with Oil Red O staining and qPCR.

Before assessing the effect of withasomniferol D (1) on adipogenesis, the 3T3-L1 preadipocytes were treated with 1 at different concentrations $(0,12.5$, and $25 \mu \mathrm{M})$ for $24 \mathrm{~h}$ to evaluate their cytotoxicity. No cytotoxic effects were observed at concentrations of up to $25 \mu \mathrm{M}$ (Figure S8). Additionally, the cytotoxicity of $\mathbf{1}$ was tested at a concentration of $25 \mu \mathrm{M}$ for $48 \mathrm{~h}$ and $72 \mathrm{~h}$, which also showed that compound 1 exhibited no cytotoxicity for $72 \mathrm{~h}$ (Figure S8). Therefore, 3T3-L1 cells were treated with 1 during adipogenesis at a concentration of $25 \mu \mathrm{M}$ to evaluate its anti-adipogenic activity in subsequent experiments. After $10 \mathrm{~d}$ of differentiation, the lipid droplets within the mature adipocytes were stained using the Oil Red O working solution [33]. Microscopic examination of the stained adipocytes revealed that compound 1 significantly inhibited adipogenesis and suppressed the accumulation of lipid droplets compared to the control setup (Figure 5B). Furthermore, the mRNA expression levels of adipocyte marker genes fatty acid-binding protein 4 (Fabp4) and Adipsin were markedly reduced following treatment with $25 \mu \mathrm{M}$ of compound 1 (Figure 5C). These results indicated that withasomniferol D (1) alleviated adipogenesis in 3T3-L1 preadipocytes. Interestingly, withasomniferol D (1) also upregulated the mRNA expression of the lipolytic genes such as hormone-sensitive lipase (HSL) and adipose triglyceride lipase (ATGL) (Figure S9). On the other hand, the mRNA expression of the lipogenic gene sterol regulatory element-binding transcription factor 1 (SREBP1) was downregulated following treatment with $25 \mu \mathrm{M}$ of $\mathbf{1}$ during adipogenesis (Figure S9). These data suggest the possibility that withasomniferol D (1) can enhance lipid metabolism by promoting lipolysis and inhibiting lipogenesis.

A

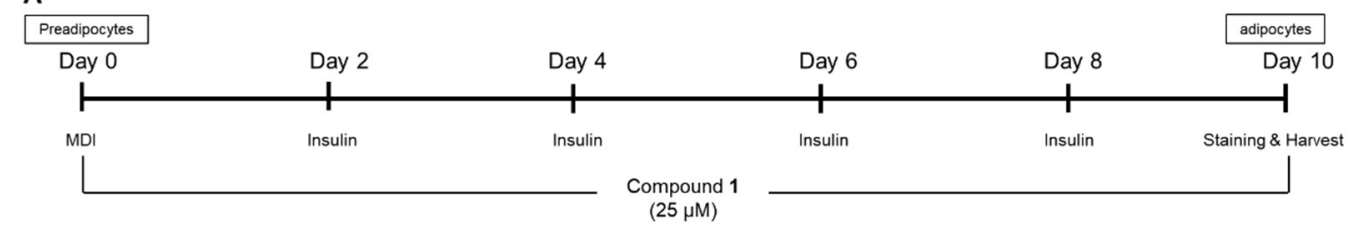

B
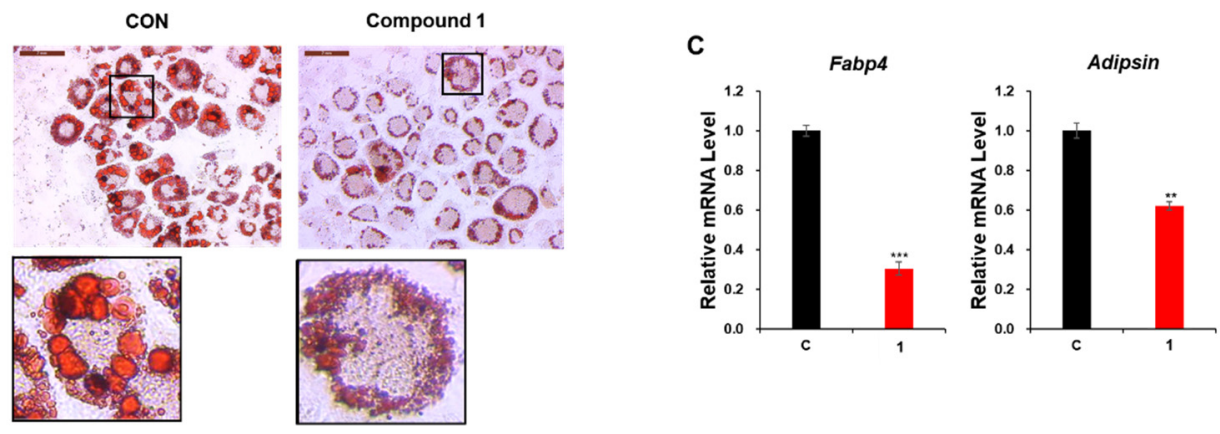

Figure 5. Inhibitory effects of compound $\mathbf{1}$ on adipogenesis. (A) Schematic representation of the differentiation of 3T3-L1 preadipocytes into adipocytes following $10 \mathrm{~d}$ of culture. The 3T3-L1 cells were treated with compound $\mathbf{1}$ during differentiation. (B) Images of adipocytes stained with Oil Red O following incubation with $25 \mu \mathrm{M}$ of compound $\mathbf{1}$ during adipogenesis. (C) The relative mRNA expression levels of the fatty acid-binding protein 4 (Fabp4) and Adipsin in 3T3-L1 adipocytes incubated with $25 \mu \mathrm{M}$ of compound 1 during adipogenesis. The data are presented as the mean \pm standard error of the mean (SEM) of $n=3$ replicates. ${ }^{* *} p<0.01$, and ${ }^{* * *} p<0.001$.

\section{Materials and Methods}

\subsection{General Experimental Procedure and Plant Material}

The information for general experimental procedure and plant material is provided in Supplementary Materials. 


\subsection{Extraction and Separation/Isolation}

The roots of $W$. somnifera $(1.3 \mathrm{~kg}$ ) were dried and crushed and then extracted with $80 \%$ aqueous $\mathrm{MeOH}(3.0 \mathrm{~L} \times 3 \mathrm{~d})$ under reflux and filtered conditions. The resultant filtrate was evaporated in vacuo using a rotavapor to generate $189 \mathrm{~g}$ of crude $\mathrm{MeOH}$ extract. The crude $\mathrm{MeOH}$ extract was then dissolved in $700 \mathrm{~mL}$ distilled water and successively solvent-partitioned with hexane, dichloromethane $\left(\mathrm{CH}_{2} \mathrm{Cl}_{2}\right)$, ethyl acetate, and butanol to obtain 3.4, 4.5, 2.0, and $18.6 \mathrm{~g}$ of solvent fractions, respectively. The LC/MS analysis of each fraction was performed using a comparison of in-house-built UV spectra library, which revealed that the expected withanolides were mainly present in the $\mathrm{CH}_{2} \mathrm{Cl}_{2}$-soluble fraction because several peaks present in the $\mathrm{CH}_{2} \mathrm{Cl}_{2}$-soluble fraction showed a UV pattern ( $\lambda_{\max }$ 200-230 nm) similar to that reported for withanolides [25] and the molecular ion peak ranging $m / z 450-530$. The $\mathrm{CH}_{2} \mathrm{Cl}_{2}$-soluble fraction (4.0 g) was subjected to silica gel chromatography column (200 g) with $\mathrm{CH}_{2} \mathrm{Cl}_{2} / \mathrm{MeOH}$ (50:1 $\left.\rightarrow 1: 1\right)$ (gradient elution solvent system) to yield seven fractions $(A-G)$. Fraction $D(160 \mathrm{mg})$ was separated by using preparative reversed-phase HPLC (Luna C18, $250 \times 21.2 \mathrm{~mm}$ i.d., $5 \mu \mathrm{m}$; Phenomenex, Torrance, CA, USA) with the $\mathrm{MeOH} / \mathrm{H}_{2} \mathrm{O}$ gradient system $(2: 3 \rightarrow 1: 0$, flow rate: $5 \mathrm{~mL} / \mathrm{min})$ to provide six subfractions (D1-D6). Subfraction D5 (22 $\mathrm{mg})$ was separated by semipreparative reversed-phase HPLC $\left(31 \% \mathrm{CH}_{3} \mathrm{CN}\right)$ to yield compound $\mathbf{1}\left(t_{R} 27.7 \mathrm{~min}, 1.0 \mathrm{mg}\right)$.

Withasomniferol D (1)

White powder; $[\alpha]_{D}^{25}+11.6(c$ 0.05, $\mathrm{MeOH})$; UV (MeOH) $\lambda_{\max }(\log \varepsilon) 205$ (3.8) nm; IR (KBr) $v_{\max } 3716,2942,2834,1697,1553,1112$, and $1025 \mathrm{~cm}^{-1}$; ECD (MeOH) $\lambda_{\max }$ $(\Delta \varepsilon) 214(+3.6), 232(-2.0), 260(+16.5)$, and $337(-20.3) \mathrm{nm} ;{ }^{1} \mathrm{H}$ and ${ }^{13} \mathrm{C}$ NMR (800 and $200 \mathrm{MHz}$, respectively), see Table 1; positive high-resolution electrospray ionization mass spectroscopy (HR-ESIMS) $m / z 509.2505[\mathrm{M}+\mathrm{Na}]^{+}$(calculated for $\mathrm{C}_{28} \mathrm{H}_{38} \mathrm{NaO}_{7}, 509.2515$ ).

\subsection{Computational Analyses}

The detailed procedure for the computational ECD analyses of compound 1 is included in Supplementary Materials.

\subsection{Cell Culture and Differentiation}

The information for cell culture and differentiation procedure of 3T3-L1 preadipocytes is described in Supplementary Materials.

\subsection{Cell Viability}

The 3T3-L1 preadipocytes were cultured, seeded in 6-well plates, and treated with various concentrations of compound $\mathbf{1}(0,12.5$, and $25 \mu \mathrm{M})$ for $24 \mathrm{~h}, 48 \mathrm{~h}$, and $72 \mathrm{~h}$. The cells were detached with a trypsin/ethylenediaminetetraacetic acid solution and diluted with phosphate-buffered saline (PBS). The number of cells was counted using the LUNA-II ${ }^{\mathrm{TM}}$ Automated Cell Counter (Logos Biosystems, Strasbourg, France).

\subsection{Oil Red O Staining}

The lipid droplets in the differentiated adipocytes were stained with the Oil Red O working solution for visualization. On day 10, the mature adipocytes were plated onto 6-well plates and fixed with 10\% formaldehyde. The fixed cells were completely covered with the Oil Red O working solution to stain the lipid droplets. Then, $1 \mathrm{~mL}$ of PBS was added to the fixed cells before being viewed under a microscope. The lipid droplets in the stained cells were visualized and photographed using a Leica DMi1 inverted microscope (Leica Microsystems, Wetzlar, Germany). The Oil Red O stock solution was prepared by mixing $75 \mathrm{mg}$ of Oil Red O powder with $25 \mathrm{~mL}$ of $99 \%$ isopropyl alcohol. Next, the stock solution $(7.5 \mathrm{~mL})$ was diluted with $5 \mathrm{~mL}$ of distilled water to prepare the Oil Red O working solution. The Oil Red O working solution was filtered immediately before use. 


\subsection{Quantitative Reverse Transcription-Polymerase Chain Reaction (RT-qPCR)}

To extract the total RNA from mature adipocytes, we used the Easy-Blue reagent (Intron Biotechnology, Seongnam, Korea) according to the manufacturer's instructions. Total RNA $(1 \mu \mathrm{g})$ was reverse-transcribed into cDNA using the ImProm-II Reverse Transcription System (Promega, Madison, WI, USA). For qPCR, the generated cDNA was mixed with KAPATM SYBR ${ }^{\circledR}$ FAST qPCR (Kapa Biosystems, Wilmington, MA, USA) and the primers for each gene. qPCR was performed using a CFX96 Touch $^{\text {TM }}$ real-time PCR detector (BioRad Laboratories, Hercules, CA, USA). The relative mRNA levels for each reaction were normalized to those of $\beta$-actin. The sequences of the used primers for qPCR are shown in Table 2.

Table 2. Sequences of the primers used for quantitative reverse transcription-polymerase chain reaction (RT-qPCR).

\begin{tabular}{|c|c|c|}
\hline Gene & Forward Primer & Reverse Primer \\
\hline$\beta$-Actin & 5'-ACGGCCAGGTCATCACTATTG-3' & 5'-TGGATGCCACAGGATTCCA-3' \\
\hline Adipsin & 5'-CATGCTCGGCCCTACATG-3' & $5^{\prime}$-CACAGAGTCGTCATCCGTCAC-3' \\
\hline Fabp4 & 5'-AAGGTGAAGAGCATCATAACCCT-3' & $5^{\prime}$-TCACGCCTTTCATAACACATTCC- $3^{\prime}$ \\
\hline SREBP1 & 5'-AACGTCACTTCCAGCTAGAC-3' & 5'-CCACTAAGGTGCCTACAGAGC-3' \\
\hline ATGL & $5^{\prime}$-TTCACCATCCGCTTGTTGGAG-3' & $5^{\prime}$-AGATGGTCACCCAATTTCCTC-3' \\
\hline HSL & $5^{\prime}$-CACAAAGGCTGCTTCTACGG-3' & $5^{\prime}$-GGAGAGAGTCTGCAGGAACG-3' \\
\hline
\end{tabular}

\subsection{Statistical Analysis}

All assays were performed in triplicate and repeated at least three times. All data are presented as the standard error of the mean (SEM) for $n=3$. Statistical significance was determined using the Student's $t$-test (two-tailed) in Excel and was assessed on the basis of the $p$-value ${ }^{*} p<0.05,{ }^{* *} p<0.01,{ }^{* *} p<0.001$ vs. the control group).

\section{Conclusions}

In this study, we identified a new withanolide, withasomniferol D (1), present in the roots of W. somnifera via an LC/MS-based analysis. The structure of the new compound, withasomniferol $\mathrm{D}$, was established by spectroscopic methods, including $1 \mathrm{D}$ and $2 \mathrm{D}$ NMR, HR-ESIMS, and ECD calculations. We found that withasomniferol D (1) effectively inhibited the differentiation of 3T3-L1 preadipocytes to adipocytes by diminishing the mRNA expression levels of Fabp4 and Adipsin. Moreover, withasomniferol D (1) also suppressed lipid accumulation in the adipocytes. Based on these findings, we conclude that withasomniferol D (1) possesses the potential to prevent adipogenesis in obesity as well as obesity-related metabolic disorders.

Supplementary Materials: The following are available online at https:/ / www.mdpi.com/article/10 .3390 / ph14101017/s1; Figure S1: High-resolution electrospray ionization mass spectroscopy (HRESIMS) data of 1; Figure S2: ${ }^{1} \mathrm{H}$ nuclear magnetic resonance (NMR) spectrum of $\mathbf{1}\left(\mathrm{CDCl}_{3}, 800 \mathrm{MHz}\right)$; Figure S3: The ${ }^{1} \mathrm{H}-{ }^{1} \mathrm{H}$ correlation spectroscopy (COSY) spectrum of $\mathbf{1}\left(\mathrm{CDCl}_{3}\right)$; Figure S4: The heteronuclear single quantum coherence (HSQC) spectrum of $\mathbf{1}\left(\mathrm{CDCl}_{3}\right)$; Figure S5: The heteronuclear multiple bond correlation ( $\mathrm{HMBC})$ spectrum of $\mathbf{1}\left(\mathrm{CDCl}_{3}\right)$; Figure S6: The rotating-frame Overhauser spectroscopy (ROESY) spectrum of $\mathbf{1}\left(\mathrm{CDCl}_{3}\right)$; Figure S7: The electronic circular dichroism (ECD) spectrum of 1; Figure S8: Cytotoxicity of compound 1; Table S1: Gibbs free energies and Boltzmann distribution of conformers 1 . General experimental procedure.

Author Contributions: Conceptualization, C.P. and K.H.K.; formal analysis, B.S.L., M.J.Y., H.K., S.R.L., S.K., J.S.Y., J.-C.K. and T.S.J.; investigation, B.S.L., M.J.Y., H.K., S.R.L., S.K. and J.S.Y.; writingoriginal draft preparation, B.S.L., M.J.Y., H.K. and K.H.K.; writing-review and editing, K.H.K.; visualization, B.S.L., M.J.Y. and H.K.; supervision, C.P. and K.H.K.; project administration, C.P. and K.H.K.; funding acquisition, K.H.K. All authors have read and agreed to the published version of the manuscript.

Funding: This work was supported by a National Research Foundation of Korea (NRF) grant funded by the Korean government (MSIT) (grant numbers 2019R1A5A2027340 and 2021R1A2C2007937). 
Institutional Review Board Statement: Not applicable.

Informed Consent Statement: Not applicable.

Data Availability Statement: Data is contained within the article and Supplementary Materials.

Conflicts of Interest: The authors declare that they have no conflict of interest.

\section{References}

1. Jayaprakasam, B.; Zhang, Y.; Seeram, N.P.; Nair, M.G. Growth inhibition of human tumor cell lines by withanolides from Withania somnifera leaves. Life Sci. 2003, 74, 125-132. [CrossRef]

2. Ganguly, B.; Kumar, N.; Ahmad, A.H.; Rastogi, S.K. Influence of phytochemical composition on in vitro antioxidant and reducing activities of Indian ginseng [Withania somnifera (L.) Dunal] root extracts. J. Ginseng Res. 2018, 42, 463-469. [CrossRef]

3. Choudhary, M.I.; Yousuf, S.; Nawaz, S.A.; Ahmed, S.; Atta, R. Cholinesterase inhibiting withanolides from Withania somnifera. Chem. Pharm. Bull. 2004, 52, 358-361. [CrossRef]

4. Mary, N.K.; Babu, B.H.; Padikkala, J. Antiatherogenic effect of Caps HT2, a herbal Ayurvedic medicine formulation. Phytomedicine 2003, 10, 474-482. [CrossRef]

5. Atta-ur-Rahman, Y.M.; Gul, W.; Qureshi, S.; Choudhary, M.I.; Voelter, W.; Hoff, A.; Jens, F.; Naz, A. Cholinesterase inhibiting Withanolides from Withania somnifera. Heterocycles 1998, 48, 1801-1811. [CrossRef]

6. Bhattacharya, S.K.; Satyan, K.S.; Chakrabarti, A. Effect of Trasina, an Ayurvedic herbal formulation, on pancreatic islet superoxide dismutase activity in hyperglycaemic rats. Indian J. Exp. Biol. 1997, 35, 297-299.

7. Dhuley, J.N. Effect of ashwagandha on lipid peroxidation in stress-induced animals. J. Ethnopharmacol. 1998, 60, 173-178. [CrossRef]

8. Bhattacharya, A.; Ramanathan, M.; Ghosal, S.; Bhattacharya, S.K. Effect of Withania somnifera glycowithanolides on iron-induced hepatotoxicity in rats. Phytother. Res. 2000, 14, 568-570. [CrossRef]

9. Ganzera, M.; Choudhary, M.I.; Khan, I.A. Quantitative HPLC analysis of withanolides in Withania somnifera. Fitoterapia 2003, 74, 68-76. [CrossRef]

10. Elsakka, M.; Grigorescu, E.; Stanescu, U.; Stanescu, U.; Dorneanu, V. New data referring to chemistry of Withania somnifera species. Rev. Med. Chir. Soc. Med. Nat. Iasi 1990, 94, 385-387. [PubMed]

11. Matsuda, H.; Murakami, T.; Kishi, A.; Yoshikawa, M. Structures of withanosides I, II, III, IV, V, VI and VII new withanolide glycosides from the roots of Indian Withania somnifera D and inhibitory activity for tachyphylaxis to clonidine in isolated guineapig ileum. Bioorg. Med. Chem. 2001, 96, 1499-1507. [CrossRef]

12. Ray, A.B.; Gupta, M. Fortschritte der Chemie Organischer Naturstoffe/Progress in the Chemistry of Organic Natural Products; Herz, W., Grisebach, H., Kirby, G.W., Eds.; Springer-Verlag: Vienna, Austria, 1994; Volume 63, pp. 1-106.

13. Ma, T.; Zhang, W.-N.; Yang, L.; Zhang, C.; Lin, R.; Shan, S.-M.; Zhu, M.-D.; Luo, J.-G.; Kong, L.-Y. Cytotoxic withanolides from Physalis angulate var. villosa and the apoptosis-inducing effect via ROS generation and the activation of MAPK in human osteosarcoma cells. RSC Adv. 2016, 6, 53089-53100. [CrossRef]

14. Habtemariam, S. Cytotoxicity and Immunosuppressive Activity of Withanoliedes from Discopodiumpenninervium. Planta Med. 1997, 63, 15-17. [CrossRef] [PubMed]

15. Budhiraja, R.D.; Sudhir, S.; Garg, K.N. Antiinflmmatory Activity of $3 \beta$-Hydroxy-2,3-dihydro-withanolide F. Planta Med. 1984, 50, 134-136. [CrossRef] [PubMed]

16. Chakraborti, S.K.; De Barun, K.; Bandyopadhyay, T. Variations in the antitumor constituents of Withania somnifera dunal. Experientia 1974, 30, 852-853. [CrossRef] [PubMed]

17. Mareggiani, G.; Picollo, M.I.; Zerba, E.; Burton, G.; Tettamanzi, M.C.; Benedetti-Doctorovich, M.O.V.; Veleiro, A.S. Antifeedant Activity of Withanolides from Salpichroa origanifolia on Musca domestica. J. Nat. Prod. 2000, 63, 1113-1116. [CrossRef] [PubMed]

18. Basso, A.V.; Leiva Gonzalez, S.; Barboza, G.E.; Careaga, V.P.; Calvo, J.C.; Sacca, P.A.; Nicotra, V.E. Phytochemical Study of the Genus Salpichroa (Solanaceae), Chemotaxonomic Considerations, and Biological Evaluation in Prostate and Breast Cancer Cells. Chem. Biodivers. 2017, 14, e1700118. [CrossRef]

19. Zhang, H.; Cao, C.-M.; Gallagher, R.J.; Timmermann, B.N. Antiproliferative withanolides from several solanaceous spicies. Nat. Prod. Res. 2014, 28, 1941-1951. [CrossRef]

20. Davis, L.; Kuttan, G. Immunomodulatory activity of Withania somnifera. J. Ethnopharmacol. 2000, 71, 193-200. [CrossRef]

21. Lee, S.R.; Kang, H.S.; Yoo, M.J.; Yi, S.A.; Beemelmanns, C.; Lee, J.C.; Kim, K.H. Anti-Adipogenic Pregnane Steroid from a Hydractinia-Associated Fungus, Cladosporium sphaerospermum SW67. Nat. Prod. Sci. 2020, 26, 230-235.

22. Lee, S.; Ryoo, R.; Choi, J.H.; Kim, J.H.; Kim, S.H.; Kim, K.H. Trichothecene and tremulane sesquiterpenes from a hallucinogenic mushroom Gymnopilus junonius and their cytotoxicity. Arch. Pharm. Res. 2020, 43, 214-223. [CrossRef]

23. Trinh, T.A.; Park, E.J.; Lee, D.; Song, J.H.; Lee, H.L.; Kim, K.H.; Kim, Y.; Jung, K.; Kang, K.S.; Yoo, J.E. Estrogenic Activity of Sanguiin H-6 through Activation of Estrogen Receptor $\alpha$ Coactivator-Binding Site. Nat. Prod. Sci. 2019, 25, 28-33. [CrossRef]

24. Yu, J.S.; Li, C.; Kwon, M.; Oh, T.; Lee, T.H.; Kim, D.H.; Ahn, J.S.; Ko, S.K.; Kim, C.S.; Cao, S.; et al. Herqueilenone A, a unique rearranged benzoquinone-chromanone from the hawaiian volcanic soil-associated fungal strain Penicillium herquei FT729. Bioorg. Chem. 2020, 105, 104397. [CrossRef] 
25. Kim, S.; Yu, J.S.; Lee, J.Y.; Choi, S.U.; Lee, J.; Kim, K.H. Cytotoxic withanolides from the roots of Indian ginseng (Withania somnifera). J. Nat. Prod. 2019, 82, 765-773. [CrossRef]

26. Baek, S.C.; Lee, S.; Kim, S.; Jo, M.S.; Yu, J.S.; Ko, Y.J.; Cho, Y.C.; Kim, K.H. Withaninsams A and B: Phenylpropanoid esters from the roots of Indian ginseng (Withania somnifera). Plants 2019, 8, 527. [CrossRef] [PubMed]

27. Kuroyanagi, M.; Shibata, K.; Umehara, K. Cell differentiation inducing steroids from Withania somnifera L.(Dun.). Chem. Pharm. Bull. 1999, 47, 1646-1649. [CrossRef]

28. Xu, Y.M.; Wijeratne, E.M.K.; Brooks, A.D.; Tewary, P.; Xuan, L.J.; Wang, W.Q.; Sayers, T.J.; Gunatilaka, A.A.L. Cytotoxic and other withanolides from aeroponically grown Physalis philadelphica. Phytochemistry 2018, 152, 174-181. [CrossRef] [PubMed]

29. Spiegelman, B.M.; Flier, J.S. Obesity and the regulation of energy balance. Cell 2001, 104, 531-543. [CrossRef]

30. Smith, U.; Kahn, B.B. Adipose tissue regulates insulin sensitivity: Role of adipogenesis, de novo lipogenesis and novel lipids. J. Intern. Med. 2016, 280, 465-475. [CrossRef]

31. Lee, K.; Seo, Y.J.; Song, J.H.; Chei, S.; Lee, B.Y. Ginsenoside Rg1 promotes browning by inducing UCP1 expression and mitochondrial activity in 3T3-L1 and subcutaneous white adipocytes. J. Ginseng. Res. 2019, 43, 589-599. [CrossRef] [PubMed]

32. Park, H.J.; Rayalam, S.; Della-Fera, M.A.; Ambati, S.; Yang, J.Y.; Baile, C.A. Withaferin A induces apoptosis and inhibits adipogenesis in 3T3-L1 adipocytes. Biofactors 2008, 33, 137-148. [CrossRef] [PubMed]

33. Yi, S.A.; Lee, J.; Park, S.K.; Kim, J.Y.; Park, J.W.; Lee, M.G.; Nam, K.H.; Park, J.H.; Oh, H.; Kim, S.; et al. Fermented ginseng extract, BST204, disturbs adipogenesis of mesenchymal stem cells through inhibition of S6 kinase 1 signaling. J. Ginseng Res. 2020, 44, 58-66. [CrossRef] [PubMed] 